\title{
INGLÊS COMO LÍNGUA FRANCA E A CONCEPÇÃO DE IDENTIDADE NACIONAL POR PARTE DO PROFESSOR DE INGLÊS: UMA QUESTÃO DE FORMAÇÃO
}

\author{
ENGLISH AS A LINGUA FRANCA AND THE NOTION OF NATIONAL IDENTITY OF ENGLISH TEACHER: A \\ MATTER OF TRAINING
}

\author{
Julia Margarida Kalva* \\ Aparecida de Jesus Ferreira \\ Universidade Estadual de Ponta Grossa - UEPG, Ponta Grossa, BR
}

\begin{abstract}
RESUMO: Este trabalho objetiva analisar como a abordagem do ensino de inglês como língua franca é entendida e como o professor percebe sua identidade nacional dentro desse processo, observando se a formação acadêmica colabora para essa nova abordagem. Pretende-se também entender se a identidade nacional do professor é valorizada. A pesquisa acontece num centro de ensino de línguas estrangeiras. A metodologia utilizada para a coleta e análise de dados é a qualitativa. O referencial teórico são trabalhos sobre identidade e ensino de inglês: Hall (1999), Woodward (2005), Moita Lopes (2008), Canagarajah (1999), Phillipson (1992), Jenkins (2006), dentre outros. Como resultado pode-se perceber que a identidade nacional do professor de inglês, bem como a abordagem do inglês como língua franca ainda não são enfatizados no processo de formação do professor. Desta forma, entende-se que o ensino de inglês acaba favorecendo o apagamento da identidade nacional do professor/aluno de inglês.

PALAVRAS-CHAVE: identidade nacional; formação de professores; inglês como língua franca.
\end{abstract}

ABSTRACT: This work aims at analyzing the way English as The Língua Franca approach is understood by the teachers and how this teacher realize his/her national identity. The research takes place at an English school which has its focus on people from the community. The methodology used is the qualitative and the theoretical basis is formed by Hall (1999), Woodward (2005), Moita Lopes (2008), Canagarajah (1999), Phillipson (1992), Jenkins (2006). Through the results we could understand that English as a Lingua Franca approach is not emphasized in the teacher training and thus national identity is being left aside.

KEYWORDS: national identity; teacher training; english as a lingua franca.

\section{INTRODUÇÃO}

Quando se aprende/ensina um idioma, não é apenas a língua ${ }^{1}$ que é repassada; as culturas estrangeiras bem como as identidades estrangeiras também influenciam aqueles que se apropriam desse novo idioma (PETERSON, 2007); e esse contexto, no caso do inglês, faz com que muitas crenças sejam criadas e recriadas reforçando a ideia de que, se o indivíduo quer pertencer ao grande grupo mundial precisa aprender a língua franca ${ }^{2}$ convencionada (CANAGARAJAH, 1999, p. 14).

Quando se aprende uma nova língua não são apenas signos que são internalizados. Como observa Rajagopalan, “a língua é muito mais que um código ou instrumento de comunicação. Ela é [...] uma das principais marcas de identidade de uma nação, povo [...]” (2003, p. 93).

Sendo assim, quando aprendemos a falar inglês nos apropriamos também de uma nova identidade. E essa nossa identidade nacional (imaginada, de pertencimento à uma nação) somada à identidade da língua estrangeira formarão uma nova identidade que coesitirá com as demais, uma vez que não podemos afirmar que quando nos apropriamos de uma identidade deixamos de possuir a que tínhamos antes (HALL, 1999).

\footnotetext{
*jmkalva@gmail.com.

1 Língua nesse contex to pode ser entendida como idioma

2 De acordo com Phillipson (1992), "A língua franca é uma língua que é usada para a comunicação entre diferentes grupos de pessoas, cada grupo falando uma língua diferente. A língua franca pode ser uma língua usada internacionalmente (ex. inglês), pode ser a língua nativa de um dos grupos, ou uma língua que não é falada por nenhum grupo como língua materna, mas possui uma estrutura e vocabulário simplificados, e é frequentemente uma mistura de duas ou mais línguas” (p.42). Nesse trabalho, utilizamos a primeira opção citada na definição de Phillipson, que remete ao uso do inglês como língua franca, a qual é utilizada por pessoas que não têm uma língua comum e se utilizam do inglês para a comunicação.
} 
Tendo isso em mente, o presente artigo tem como propósito analisar como um professor de inglês em formação percebe sua identidade dentro do processo de ensino/aprendizagem, bem como observar como ele entende a concepção de ensino de inglês como língua franca; pontuando a maneira como sua formação aborda esses conceitos.

\section{IDENTIDADE NACIONAL: COMO O INGLÊS COMO LÍNGUA FRANCA SE APRESENTA}

O ensino de uma língua é muito mais complexo do que apenas levar o aluno a aprender palavras, gramática e fonética. Dentro do contexto de aprendizagem de um idioma nem sempre o processo é harmônico; muitas pessoas se sentem invadidas em sua identidade nacional quando estão aprendendo uma nova língua, principalmente o inglês. Um exemplo a esse respeito pode ser visto quando Fernandez e Fogaça (2009) apontam para uma necessidade, quanto aos alunos do primeiro e do quarto ano de Letras, de se tratar o inglês como língua franca, ou seja, respeitando aspectos locais dos aprendizes (suas identidades).

Mas algumas crenças focadas no inglês padrão ainda prevalecem, pois a pesquisa desses autores demonstrou que há uma grande quantia de alunos que veem a necessidade de se falar como o nativo para se ter status. Essa dicotomia pode ser bem percebida na seguinte passagem concernente à análise levada a cabo pelos autores:

O que existe é um conflito cultural e ideológico: os estudantes avaliam ser importante utilizar o idioma
para falar sobre assuntos pertinentes à própria realidade sociocultural e dos países que usam o inglês
como língua internacional, mas eles também desejam conhecer, e em alguns casos assimilar, a cultura
dos países do centro. Dessa forma, os alunos valorizam materiais que tratam de sua realidade, mas
também anseiam por conhecer a cultura e o maior número possível de variantes linguísticas dos países
do "inner circle". Embora os aprendizes possam sentir algum tipo de imposição ideológica por parte
desses países, que afeta seu sistema de valores e identidade, eles sabem que precisam da língua inglesa
para conseguir maiores e melhores oportunidades profissionais. (FERNANDEZ; FOGAÇA, 2009,
p.218).

Desse modo, há outras pessoas que se veem deslumbradas pela cultura/identidade do outro e acabam por desvalorizar a sua. E esse deslumbramento é um dos fatores que ajudam na construção de crenças que muitas vezes supervalorizam o falante nativo do inglês (Estados Unidos/Inglaterra) e o ambiente no qual eles vivem. Essa supervalorização do falante nativo favorece a manutenção da crença de que para se falar bem o inglês o indivíduo tem a necessidade de se tornar membro de um desses países; por essa perspectiva, muitos deixam de valorizar sua identidade local, ou nacional (PHILLIPSON,1992).

Quando falamos em globalização, logo pensamos na união dos povos em um grande grupo; essa união imaginada fez com que ocorresse, de uma certa forma, uma homogeneização cultural e identitária, na qual todas as pessoas necessitariam falar a mesma língua para se comunicar e assim pertencer a esse grupo, devendo comer a mesma comida, assistir aos mesmos programas etc. Contudo, essa união imaginada não acontece sem críticas, como ressalta Kumaravadivelu se o processo de globalização aproximou culturas e pessoas, por outro lado, ele também produz uma " $[\ldots]$ consciência dos valores e visões de cada um e a uma decisão mais firme de preservar e proteger a própria herança linguística e cultural (KUMARAVADIVELU, 2006, p.135).

Como podemos notar, o processo de globalização fez com que as pessoas passassem a pertencer ao todo e isso trouxe um sentimento de homogeneização que incomoda e faz com que valorizar o local, aquilo que é característico de mim e me faz diferente do outro, também passe a ser considerado e atue como forma de preservar a identidade nacional. E a língua materna, por ser uma das formas mais evidentes de se mostrar a identidade, passa a ser mais valorizada (KALVA; FERREIRA, 2011).

Um exemplo disso pode ser visto no trabalho de Assis-Peterson (2008). Através de entrevistas feitas com donos de estabelecimentos comerciais que têm nomes em inglês, ela faz um levantamento e análise dos nomes dados por eles, de por que usam a língua inglesa, e de como se sentem com relação a ela. A autora conclui que os donos de estabelecimentos usam o inglês porque a consideram uma língua de prestígio e porque a veem como perpassada pela ideia de modernidade; apesar disso, contudo, a ortografia e até aspectos gramaticais e fonéticos são abrasileirados, mostrando que o fato de o brasileiro usar o inglês não 
quer dizer que tente mudar de identidade e sim agregar mais identidades àquela já existente, transformando uma língua com identidade estrangeira em uma língua híbrida formada também pela identidade nacional dos sujeitos (ASSIS-PETERSON, 2008.)

A língua como sendo um símbolo de identidade nacional, ou seja, do local, passa, portanto, a ser mais valorizada e, conforme aponta Rajagopalan, "Da mesma forma que o sentimento de amor à pátria passa pelo amor à língua materna, o sentimento de chauvinismo [...] aflora por intermédio de um ódio desmedido à língua estrangeira" (RAJAGOPALAN, 2003, p. 93).

Então, para que essa crise diminua há que se buscar uma identidade que possa unir as pessoas e que as faça voltar a sentir a falsa segurança de pertencimento que foi perdida com a fragmentação das identidades. Esse sentimento de unidade é uma fantasia que nos faz sentir bem e valorizar o local, ou o nacional, em detrimento do global (HALL, 1999).

Apesar desse movimento de valorização da língua materna, também há, em nossa cultura atual, o sentimento de pertencimento ao global muito forte e a aprendizagem da língua inglesa não só representa pertencer ao global, mas também está relacionada ao sentido de ascensão a uma vida melhor (KALVA; FERREIRA, 2011).

Falar uma língua estrangeira, muitas vezes, faz com que a pessoa seja mais valorizada, isso devido à crença ${ }^{3}$ de que o estrangeiro é melhor que o nacional (BARCELOS, 2004). Essa crença está enraizada em nossas mentes há anos, e a mídia é uma das grandes responsáveis pela sua criação, uma vez que ela vê o ensino de inglês como uma mercadoria, de modo que, para vendê-la, não mede esforços em valorizá-la (RAJAGOPALAN, 2004).

Assim, para que se pertença de forma completa ao "global", que Kumaravadivelu (2006) chama de americanização, acredita-se, popularmente e mesmo nos meios acadêmicos, que não basta apenas "dominar" o idioma e conseguir comunicar-se através dele; o falante precisa falar como o nativo, ou seja, deve buscar ser o mais próximo possível do que o nativo é.

Pensando que a identidade nacional do sujeito também é marcada pela língua estrangeira e vice-e-versa, esse conflito de identidades exerce influência sobre o processo de ensino-aprendizagem. Por isso se faz necessário pensar em questões como essas para o trabalho em sala de aula, e muitos trabalhos têm sido feitos com o intuito de repensar o aluno não só como aquele que aprende uma língua para mera comunicação, mas também como um indivíduo que participa ativamente do processo de re(construção) de sua(s) identidade(s) durante a aprendizagem de uma nova língua (KALVA; FERREIRA, 2011).

Assis-Peterson (2007) é uma das autoras que trata dessa questão do inglês como língua estrangeira dentro da globalização. Como bem aborda a autora, o problema não é haver uma língua comum (franca) para uma comunicação de fronteira; o problema é o anglicismo que acaba por diminuir o multilinguismo, mas que, ao mesmo tempo, também pode ser usado como forma de comunicação em um mundo globalizado, ou mundializado como ela prefere se referir ao fato de fronteiras serem porosas. A autora critica, em seu trabalho, a forma como a língua inglesa é vendida e consumida sem que haja um questionamento acerca das consequências de se consumir não somente uma língua, mas também toda a bagagem cultural e identitária que ela carrega.

Por outro lado, Moita Lopes (2008), ao aborda ideologia linguística e globalização, defende que, apesar de língua inglesa ser uma das companheiras do império, ela já não pode mais ser considerada patrimônio de um único país, posto que já há mais falantes não nativos do que nativos de inglês, de modo que o local passa a adaptar o inglês aprendido à sua maneira.

A noção de que inglês correto é aquele que se iguala ao do nativo já está, portanto, sendo questionada, "o falante nativo parece ter perdido a prerrogativa exclusiva de controlar a padronização" (PENNYCOOK, 1994, p.10). Dessa forma, deixando que o idioma seja permeado por características locais, o inglês deixa de

\footnotetext{
3 Adotamos, neste trabalho, a concepção de crença de Barcelos (2004): "Uma forma de pensamento, como construções da realidade, maneiras de ver e perceber o mundo e seus fenômenos, co-construídas em nossas experiências e resultantes de um processo interativo de interpretação e (re) significação. Como tal, crenças são sociais (mas também individuais), dinâmicas, contextuais e paradoxais".
} 
ser visto como língua local, para ser uma língua mundial, hibridizada, na qual se mesclam o global com o local (cf. MOITA LOPES, 2008; ASSIS-PETERSON; COX, 2008; HOUSE, 2003).

Kramsch e Sullivan (1996), em um estudo com alunos universitários, puderam observar que o uso do inglês por parte desses alunos mantinha características culturais vietnamitas, o que apontou para o fato de que os alunos conseguiam se comunicar tanto com falantes globais quanto com locais, ou seja, o ensino da língua os preparava para a comunicação tanto com pessoas de países com culturas diferentes da sua quanto com pares de sua própria cultura, mantendo assim sua identidade.

Dentro dessa discussão, cabe ressaltar que o inglês como língua internacional ou como língua franca vem tomando força ultimamente. Salles e Gimenez (2008) salientam que "a transição de falantes de inglês de língua estrangeira para segunda língua vem crescendo tão rapidamente que já se pode esperar um grande número de variedades linguísticas de falantes não nativos." (SALLES; GIMENEZ, 2008, p.27).

Para Graddol (2006), o número de falantes de inglês de L1 e L2 não varia muito, contudo, quando se fala de inglês como língua franca, pode-se perceber uma tendência a crescer com maior velocidade, o que também ressalta a importância de se prestar mais atenção a essas novas concepções de língua e identidade, pois estamos presenciando uma nova concepção de língua: a glocal, o uso do inglês para a comunicação com pessoas que não têm línguas em comum, e preservam suas identidades locais (PAKIR, 1997).

Analisando a língua inglesa como sendo uma língua franca, podemos notar um dado paradoxal: o aumento do inglês como língua franca pode estimular os membros de línguas minoritárias a investirem em suas línguas locais, reforçando, assim, sua identidade nacional, representada pela língua (CANAGARAJAH, 2006). Block (2004), fazendo um levantamento bibliográfico de como está ocorrendo o uso de inglês na internet, percebe esse fenômeno, quando conclui que, apesar de o inglês ter sido a primeira língua a ser usada nesse novo meio de comunicação, ela não permaneceu como sendo a única.

Para House, a língua inglesa tem sua força, contudo não consegue criar raízes. Ela é usada para negócios, ciência, economia e educação, porém não tem a mesma carga identitária que a língua local apresenta (HOUSE, 2003, p.561); e, vista desta forma, a língua inglesa não pode ser considerada uma ameaça às outras línguas, pois é mais usada como forma de comunicação do que de identificação (HOUSE, 2003).

A noção de inglês como língua franca passou a apontar para novas características necessárias para a comunicação. Canagarajah (2007, p.925) afirma que "o inglês como língua franca pertence a um discurso virtual, no qual os falantes não estão locados em uma determinada área, mas eles habitam e praticam outras línguas e culturas em sua própria localidade imediata”.

Nessa perspectiva, não se pode pensar em inglês como homogêneo, mas sim plural, de forma que os vários participantes criam suas próprias variedades de inglês (CANAGARAJAH, 2007), no mesmo instante em que criam e recriam suas identidades, pois pensando o inglês de forma multilinguística também podemos percebê-lo como espaço para uma multiplicidade de identidades e não apenas uma considerada como certa (PENNYCOOK, 1994).

Então vemos agora que não se pode pensar que há apenas uma variedade de inglês, mas sim várias, baseadas em cada local onde o inglês é falado, como observa Canagarajah (2007, p.927): "o contexto de comunicações globais e interculturais é imprevisível, e a mistura de participantes e motivos para a comunicação têm que ser analisada em circunstancias reais". Além disso, para que haja de forma efetiva a comunicação, é necessário interação e negociação por parte dos falantes (cf. CANAGARAJAH, 2007, 2006; JENKINS, 2006; SEIDLHOFER, 2004), levando sempre em consideração o ambiente e identidades que se cruzam ato da comunicação.

Nesse momento, a língua inglesa não faz mais parte desse império (americano/britânico) e passa a ser patrimônio de todos. Contudo, ainda falta ser trabalhada essa concepção não somente dentro de sala de aula, mas em outros espaços da sociedade, para que se possa acabar com o mito do anglicismo, ou nativo como o melhor, e para tanto:

Qualquer pedagogia pensada para esses alunos terá que considerar o desejo de dominar o idioma, mas também seus medos de hegemonia linguística e ideológica, e terá que sugerir uma maneira de reconciliar esses conflitos. (CANAGARAJAH, 1999, p.74). 
Consequentemente, a formação de professores críticos que consigam lidar tanto com suas identidades quanto com as de seus alunos em sala de aula se faz necessário para que o ensino se torne mais significativo. E para tanto, não se pode deixar de considerar como as crenças de alunos e professores se apresentam no contexto de ensino/aprendizagem.

\section{O ENSINO DE INGLÊS TRATADO COMO LÍNGUA FRANCA E A SUA ABORDAGEM NA FORMAÇÃO DE PROFESSORES}

Ainda é marcante em nossa sociedade a noção de que países como Estados Unidos e Inglaterra são detentores de uma cultura única e fixa; situação que colabora para a manutenção de uma longa história de colonialismo. Dessa maneira, percebemos a ocorrência de uma dicotomia entre os países de cultura diferente da americana/britânica, apresentados com uma imagem exótica e estranha, não "normais”, enquanto os países nativos da língua inglesa são mostrados como modernos, o padrão a ser seguido, ou seja, normais (PENNYCOOK, 1994).

Vemos que “[ ...] a crença de que o falante nativo é dono da língua persiste entre professores nativos e não nativos, educadores e linguistas, mesmo sendo ela agora apresentada com mais sutileza do que antes [...] (JENKINS, 2006, p.171). Outro fator que ainda permanece é a ideia de inglês monolítico (standard), no qual a variedade linguística não existe. Esse inglês padrão pode ser considerado quando se fala da escrita, posto que o indivíduo tem tempo para reconsiderar e tentar apagar as características identitárias presentes no texto. Entretanto na fala é mais difícil de apagar esses traços uma vez que a pessoa não tem tempo suficiente para considerar esses aspectos, sendo, então, denunciada pela pronúncia e escolha lexical feita no momento da fala (SEIDLHOFER, 2004).

Ainda é muito forte a concepção de inglês padrão dentro do meio educacional, tanto de ensino de línguas quanto de formação de professores. Por outro lado, muitos pesquisadores de inglês como língua franca não acreditam que tal variedade monolítica de inglês possa alguma vez ter existido. Jenkins comenta que:

[a]o invés de pensar em uma única variedade de inglês, eles acreditam que qualquer pessoa que participa da comunicação internacional precisa familiarizar-se, e ter em seu repertório linguístico para uso, certas formas (fonológicas e lexicogramaticais, etc.) que são amplamente usadas e inteligíveis dentre grupos de falantes de inglês vindos de diferentes línguas maternas (JENKINS, 2006, p.157).

Portanto é ingênuo se pensar que aprendendo somente uma variedade da língua inglesa podemos nos comunicar perfeitamente com o global. Nesse sentido, “[ [...] professores e alunos concordam que não precisam aprender uma variedade de inglês, mas sim sobre as variedades de inglês, suas similaridades e diferenças, temas envolvendo inteligibilidade, e a forte ligação entre língua e identidade” (JENKINS, 2006, p.173), para que possam de forma eficaz se comunicar.

Sendo assim, no “[ [...] contexto escolar, estudantes e professores têm desenvolvido estratégias similares para negociar valores locais e identidades face às políticas discursivas [...]” (CANAGARAJAH, 2006, p.203). Vemos, pois, a língua local ser introduzida no ensino de língua estrangeira sutilmente com o intuito de negociar valores desejados, identidades e interesses.

As variedades de inglês começam a ser vistas de forma positiva e o estigma de que a língua inglesa falada com sotaque local é inferior vai sendo deixado de lado, partindo-se para um espaço onde essas variedades são apresentadas e trabalhadas no âmbito de ensino (CANAGARAJAH, 2006). Por essa nova perspectiva de ensino, cada falante e aprendiz de inglês deveria refletir sua própria realidade linguística, ao invés de se pensar, no ensino, apenas na realidade do falante nativo (JENKINS, 2006, p.173).

Seidlhofer (2004) comenta que essa abordagem precisa considerar a natureza transcultural do uso de inglês em comunidades multilinguísticas, o questionamento do modelo de ensino baseado no falante nativo, e o reconhecimento das variedades de inglês que resultaram na expansão global da língua. Nesse contexto, o ensino deveria ser pensado de forma diferente: a inteligibilidade enfatizada em detrimento da eficácia exacerbada; o aumento na competência textual; a sensibilidade na escolha do conteúdo cultural nos materiais didáticos; a reflexão nos procedimentos pedagógicos; e o respeito à cultura local do aprendiz (SEIDLHOFER, 2004, p.225). 


\section{METODOLOGIA DE PESQUISA}

Neste trabalho a abordagem qualitativa foi escolhida devido a suas características, particularmente a subjetividade: o pesquisador torna-se peça chave no momento de análise dos dados, pois não se pode colocar em números precisos o que foi pesquisado; dessa maneira a subjetividade do pesquisador é colocada dentro da análise dos resultados. O processo e o significado são os focos principais dessa abordagem (GIL,1999). Além disso, a análise qualitativa é um teste de habilidade de pensar e processar informações de maneira útil e significativa, na qual o ambiente onde ocorre a pesquisa é de grande importância para a interpretação dos dados coletados (ROBSON, 2002).

Para a geração de dados, utilizamos a entrevista e o questionário. O questionário é o instrumento de coleta de dados constituído por uma série ordenada de perguntas que devem ser respondidas com ou sem a presença do pesquisador (MARCONI; LAKATOS, 1986). Ele pode ser administrado em interação pessoal em forma de entrevista individual ou por telefone, e pode ser auto-aplicável (GUNTHER, 2003, p.2). A apresentação dos itens de uma survey pode ser conceitualizada como um estímulo de que se espera alguma resposta que por sua vez precisa, de alguma maneira, ser registrada para poder ser analisada. Logo, há potencialmente três atores envolvidos direta ou indiretamente: quem administra o instrumento, quem responde ao instrumento e quem transcreve a informação registrada no instrumento para o processamento e análise dos dados (GUNTHER, 2003).

A entrevista tem uma grande variedade de formas e usos; o tipo mais comum de entrevista é o individual, face a face, com trocas verbais, mas ela também pode tomar a forma de entrevista de grupo, na qual o entrevistador tem a oportunidade de questionar várias pessoas ao mesmo tempo. Além disso, a entrevista pode ser considerada como estruturada, semi-estruturada, ou sem estrutura (DEZIN; LINCOLN, 1996, p.48).

Neste trabalho, utilizamos a entrevista em sua forma semi-estruturada. Nesse tipo de entrevista, o pesquisador formula, previamente, uma sequência de perguntas, mas está livre para modificar a ordem dependendo de como a entrevista acontece, deixando aquelas mais apropriadas ao contexto. Portanto, o entrevistador, dependendo do contexto e da maneira como a entrevista está acontecendo, pode deixar de lado algumas perguntas, bem como acrescentar outras (ROBSON, 2002).

O contexto em que foi realizada a pesquisa é um centro de línguas estrangeiras voltado para a comunidade, tendo como professores os acadêmicos do curso de Letras da instituição. O curso de idiomas tem por objetivo tanto contribuir para a formação dos futuros professores como proporcionar um curso de qualidade e acessível à comunidade.

A pesquisa realizada foi primeiramente levada à apreciação do comitê de ética da Universidade Estadual de Ponta Grossa e foi considerada aprovada de acordo com a resolução 196 de 1996 sobre ética em pesquisa. Com esse procedimento, nos pautamos por um código de conduta buscando resguardar os sujeitos participantes em relação a subjetivações inerentes à pesquisa qualitativa.

\section{ANÁLISE E RESULTADOS}

Para uma melhor compreensão dos resultados, inicialmente delineamos o perfil da professora que participou da pesquisa piloto que serviu de base à discussão aqui proposta. A docente participa de um projeto de ensino de línguas estrangeiras para a comunidade, no qual atua como professora de níveis iniciais de inglês. Ela cursa o segundo ano de licenciatura em Letras Português/Inglês de uma universidade do sul do Brasil e diz ter escolhido a profissão por achar dinâmico o processo de ensino/aprendizagem devido a constante mudança que a língua sofre em seu uso. Quanto ao tempo de estudo da língua, a professora afirmou que estuda o idioma há 8 anos, dos quais 3 foram feitos no exterior (Estados Unidos), onde fez curso de inglês como intercâmbio, para aprimorar sua fluência.

Depois de respondido, o questionário, os temas abordados nas respostas dadas à pesquisa foram divididos em tópicos para melhor visualização dos resultados. A entrevista com a professora foi realizada no dia 29 de março de 2011. 


\subsection{Importância de se ter sotaque de falante nativo}

Para muitos, ter sotaque exatamente igual ao do nativo da língua que está sendo aprendida é fator crucial para se ter uma boa fluência, o que acarreta a necessidade de um apagamento do sotaque da língua materna. Essa questão está relacionada à busca por uma outra identidade que não aquela vinda com a língua materna; essa outra identidade pode ser vista como uma mescla de identidades que resulta na formação de uma nova ou como rejeição à identidade nacional do aprendiz para adquirir a identidade estrangeira/do outro.

Quando a professora foi questionada com relação a se falar ou não com sotaque de falante nativo, num primeiro momento ela enfatizou que "a importância de se ter sotaque nativo é indiferente", pois nunca iremos ter sotaque exatamente igual a um nativo e mesmo não falando igual a eles as pessoas conseguem nos entender, como pode ser visto a seguir:

Pesquisadora: Você acha importante ter um sotaque de inglês nativo?

Profa: Kate ${ }^{4}$. uhum...pra mim é indiferente, porque a gente nunca vai falar igual ao nativo...e mesmo que não fale igual eles vão entender a gente. ${ }^{5}$

Entretanto, quando questionada sobre seu sotaque ela comenta que é interessante ter sotaque de nativo:

Pesquisadora: Você tem sotaque de nativo? Acha importante ter?

Profa. Kate: a importância que tem um pouco, é devido a minha estadia por 3 anos estudando inglês nos Estados Unidos é que ter esse sotaque é, apesar de não ser essencial, bastante interessante para o professor de inglês.

Para a entrevistada esse fator parece ser bastante relevante, pois, segundo ela, quando se estuda uma língua já se tem a ideia de ir para o país onde se fala essa língua; e então é importante não ser tão diferente o sotaque para que o nativo melhor entenda o que se quer dizer.

Pelas respostas da professora podemos perceber ainda muito forte a concepção de que é preciso se parecer com o falante nativo para falar bem, o que pode também gerar a vontade de se desfazer, como se fosse possível, da identidade nacional (representada pelo sotaque da língua materna) para buscar uma nova tida como mais valorizada como parece ser a dos falantes de língua inglesa, o que pode ser percebido também nas pesquisas de Fernandez e Fogaça (2009).

\subsection{Enfâse na cultura dos países do centro (Estados Unidos/Inglaterra)}

Falando de um dos materiais didáticos que mais servem de apoio para o professor e alunos na aula de inglês, o livro didático, pode-se notar que a professora não percebe de forma significativa as questões culturais dentro do livro.

Quando questionada a respeito de como o livro aborda as questões culturais, a docente comenta que nem todos trazem aspectos culturais e quando o fazem enfatizam apenas a cultura americana ou britânica, e que a cultura brasileira muito raramente aparece nos livros. Porém o que mais chama a atenção é que a professora concorda com essa posição:

Pesquisadora: E você acha adequado não ter a cultura brasileira no livro didático?

Profa. Kate: Não tem que ter cultura brasileira, porque a nossa nós já conhecemos, tem que aprender a cultura da língua que estamos aprendendo.

Pela fala da professora, podemos identificar a noção de que temos que partilhar da identidade nacional dos falantes nativos para podermos falar a língua de forma adequada. E a identidade nacional do aluno/professor pode ser deixada de lado, posto que ela não colabora para falar fluentemente o idioma estrangeiro. As respostas da Profa. Kate se mostram bem evidentes e se coadunam com as descobertas de Moita Lopes (1996) quanto à concepção corrente de que se faz necessário aprender a cultura do falante

\footnotetext{
4 Por uma questão de ética o nome utilizado é fictício.

5 Para diferenciar da citação, presentamos os dados coletados em itálico.
} 
nativo para se ter uma boa fluência na língua. Cabe aqui ressaltar que os países nativos nesse contexto são na maior parte do tempo restritos a dois, Inglaterra e Estados Unidos, o que propicia ainda mais a supervalorização desses países e abre brechas para o inglês ser visto pela perspectiva do imperialismo linguístico, conforme abordado por Pennycook (1994)

Embora não consiga visualizar e nem veja necessidade de se falar do Brasil dentro do livro didático, a professora comentou que durante as aulas a identidade nacional brasileira é abordada com frequência, por meio de comparações entre o que acontece nos países nativos de língua inglesa e no Brasil. Por exemplo, como são os feriados em cada país, as diferenças gramaticais entre as línguas e o estilo de vida de cada lugar.

Quanto às representações relativas aos Estados Unidos e Inglaterra (os quais ao ver da professora são os países mais evidentes) e ao Brasil, ela assim se manifesta:

Pesquisadora: Você concorda com a representação que aparece do Brasil nos livros didáticos?

Profa.Kate: A representação não é só boa nem só má, pois se fala de tudo do Brasil, e só é falada a realidade.

Ela parece pensar que a representação dos países do centro (Estados Unidos/Inglaterra), apesar de ser um pouco “enfeitada” para valorizá-los, é pertinente, uma vez que realmente esses países têm mais história e são mais avançados que o Brasil.

Essas concepções nos apontam que as crenças sobre os países do centro, as enfatizadas pelo livro didático, são ainda mais reforçadas pela crença da professora sobre o que é o Brasil e os países falantes de inglês. As representações colaboram para o pensamento de que, quando fala inglês, a pessoa terá certa ascensão para uma vida melhor. As respostas dadas pela profa. Kate corroboram o que outras pesquisas recentes mostram, como é o caso de Pennycook (1994), Assis-Peterson (2008), Jenkins (2006).

\subsection{Professor nativo ou que morou no exterior: melhor ou pior que o não nativo, ou aquele que não morou no exterior}

Para a entrevistada, o professor nativo não é necessariamente melhor que o não nativo. Em níveis iniciais ela acredita que o professor não nativo é melhor, pois pode falar na língua materna do aluno, entretanto em níveis mais avançados ela julga que o professor nativo ou aquele que estudou/morou fora é mais interessante, pois pode transmitir melhor a cultura do país da língua que está ensinando. Indagada sobre estudar no exterior, ela responde enfatizando a questão da fluência:

Pesquisadora: Você acha que estudar inglês no exterior é melhor?

Profa. Kate: ir ao exterior para aprender inglês é bom porque pega fluência na língua e convivência com a cultura.

Levando em consideração essa resposta, pode-se perceber que a entrevistada avalia como bom professor aquele que privilegia o falante nativo como o ideal a ser seguido, indo de encontro ao que prega o ensino de inglês como língua franca, o qual enfatiza o ensino de inglês de forma mais plural respeitando as variedades que essa língua pode apresentar devido a seu caráter global (cf. JENKINS, 2006; CANAGARAJAH, 2007; e HOUSE, 2003).

Nesse viés, nota-se que a concepção de ensino de língua inglesa da professora ainda está muito relacionada ao ensino de inglês como língua estrangeira e não como língua franca. Isso se deve talvez ao fato de a professora ser aluna do segundo ano de Letras e, em razão disso, pode ainda não ter discutido questões de inglês como língua franca; o que remete à pesquisa de Fernandez e Fogaça (2009).

\subsection{Questionamentos sobre identidade nacional e língua franca na graduação}

Quando questionada sobre o conceito de inglês como língua franca, a professora se mostrou um pouco insegura.

Pesquisadora: o que você entende por língua franca? Já ouviu falar na sua formação acadêmica? 
Profa Kate: Ah! Sim inglês usado por todos né...isso é verdade e precisa falar pro aluno que ....por isso que ele tem que estudar...

Na graduação falamos da importância de estudar inglês...que ele é usado no mundo todo...

A princípio, ela não tinha muito claro o que vinha a ser essa nomenclatura, para ela língua franca e língua estrangeira eram equivalentes; esse ponto pode apontar para uma falta de discussões a respeito desse tema durante a formação. ${ }^{6}$

Pesquisadora: você já discutiu a questão da identidade nacional na graduação?

Profa Kate: não lembro de ter discutido isso em sala...mas acho importante que se fale da cultura pra que a gente possa fazer contrapontos quando estamos dando aula...fica mais interessante pro aluno....

Com relação ao tema identidade nacional, ela enfatiza que não lembra de ter tido discussões sobre esse tema, mas acha interessante que o professor estabeleça em sala de aula contrapontos entre a cultura "deles" e a nossa.

Percebe-se então que discussões relativas à identidade e ao ensino de inglês como língua franca ainda não são tão enfatizados nos primeiros anos de graduação e que isso pode influenciar na forma como o professor trabalha em sala. Assim, os docentes podem continuar por vezes a disseminar crenças nem sempre pertinentes ao processo de ensino/aprendizagem.

\subsection{A representação do Brasil e de outras nações na opinião do professor}

Um fator que pode influenciar muito no transcorrer das aulas e alimentar ou criar crenças nos alunos é a visão que o professor tem de sua identidade nacional representada pelo país em que vive. No caso da professora participante da pesquisa, pode-se notar que ela apresenta um olhar viesado em relação ao Brasil e um encantamento com países falantes de inglês, em especial os Estados Unidos. Vejamos:

Pesquisadora: Como você caracteriza o Brasil?

Profa. Kate: um país razoável de se viver, com muitas precariedades na saúde, educação etc., só é bom viver aqui por causa da família e amigos

Ou seja, o Brasil não oferece muito a ela, enquanto outros países falantes de língua inglesa, sim:

Pesquisadora: Como você caracteriza os países falantes nativos da língua inglesa?

Profa. Kate: São melhores que o Brasil, tem coisa ruim lá também, mas saúde e educação são bons. A cultura deles é mais rica, tem mais história que nós.

Além disso, ela acha que por ter morado 3 anos nos Estados Unidos já incorporou elementos da cultura americana, como fazer sua filha dormir às $9 \mathrm{~h}$ da noite, o que, ao ver da professora, é um comportamento mais disciplinado que aquele apresentado por brasileiros.

Esses comentários apontam para uma supervalorização da cultura americana em detrimento da cultura brasileira, mostrando o quanto a identidade nacional brasileira pode ser vista como uma identidade diminuída. Essa visão contribui para a manutenção da concepção de que o estrangeiro é melhor. Resultados semelhantes podem ser encontrados nas pesquisas desenvolvidas por Moita Lopes (1996) e por Ferreira (2000). Os resultados obtidos, em termos dos professores pesquisados, demonstraram supervalorização dos Estados Unidos e da Inglaterra: aquilo que se relaciona a aspectos positivos (ex: honesto, educado, trabalhador, realista, formal, disciplinado) está ligado aos americanos e ingleses, enquanto os aspectos negativos (mal-educado, preguiçoso, informal, indisciplinado) são associados aos brasileiros.

\footnotetext{
${ }_{6}$ Cabe salientar aqui que a professora pesquisada ainda está em processo de formação e talvez venha a ter discussões relativas a esse tema mais tarde durante a graduação.
} 


\section{CONSIDERAÇÕES FINAIS}

Apesar de a pesquisa ter sido feita com apenas uma professora, podemos notar que algumas crenças com relação ao ensino de inglês como língua franca e a identidade nacional são fatores presentes no ensino/aprendizagem e podem influenciar na forma como o professor e os alunos se relacionam com a língua inglesa. A pesquisa também consegue replicar outros resultados de pesquisas realizadas em outros contextos no Brasil.

Pelas respostas dadas pela docente, pode-se perceber que o falante nativo ainda parece ser tido, nas crenças, como o padrão a ser seguido. Ter o sotaque parecido com o do nativo; para se falar bem é necessário ir ao país de origem da língua que está sendo estudada; manter o sotaque da língua materna do aluno/professor não é adequado para se ter fluência - crenças como essas vão de encontro ao que se privilegia no ensino de inglês como língua franca. Essa abordagem vê o inglês como pertencente a todos sem que se dê mais ênfase a um ou outro sotaque ou a uma ou outra identidade; pelo contrário, quanto maior o número de identidades e sotaques que aparecerem no ensino, mais hábil estará o aluno comunicar-se com o mundo.

Entretanto, é importante salientar que em alguns momentos a professora diz que não se consegue perder totalmente o sotaque de origem (dos alunos e dela mesma), apesar de se tentar, e que isso não influencia para uma boa comunicação, apontando para uma consciência, mesmo que vaga, de que apagar o sotaque não seja necessário para a compreensão entre falantes da língua. Na verdade, o que mais a preocupa é a questão do pertencimento, pois para ela é preciso se parecer com o falante nativo para ser aceito no grupo, e, na sua opinião, o grupo de fora é melhor do que aquele em que ela vive, no caso o Brasil.

Por essa perspectiva, podemos entender que a identidade nacional da professora é um tanto desvalorizada quando comparada à identidade do falante nativo. Para ela, a vida nos países de língua inglesa, por exemplo Estados Unidos ou Inglaterra, é muito melhor do que a vida no Brasil e até mesmo do que em outras culturas, uma vez que ela não vê a necessidade de se estudar outras variedades de inglês, mesmo de outros países onde o inglês é língua oficial:

Pesquisadora: Você acha importante estudar outras variedades de inglês?

Profa. Kate: A gente estuda inglês pensando em ir, principalmente, para os Estados Unidos e Inglaterra. Então tem que estudar o inglês padrão, tanto na gramática como no listening.

Portanto, entendemos que a formação do professor pode ser uma peça fundamental para que se repense crenças enraizadas sobre o que seja um bom professor e sobre como tornar a sala de aula um local que ofereça condições para que os alunos se exercitem como cidadãos do mundo, tendo contato com a diversidade e a multiplicidade de culturas que a língua inglesa propicia, e não como falante nativo, ou seja, outra pessoa.

Então para que o ensino de inglês seja adequado ao pensamento de inglês como língua franca é conveniente que sejam revistos alguns conceitos que temos sobre aprender/ensinar inglês. Jenkins (2006) e Seidlhofer (2004), por exemplo, falam dos erros ligados à ideia de que há um inglês padrão, e que é necessário corrigir tais erros para que haja uma boa comunicação. Isso, todavia, não é necessariamente verdadeiro, uma vez que eles não atrapalham o entendimento e podem ser negociados dentro da conversação.

Erros típicos que a maioria dos professores de inglês corrigiria imediatamente, e com os quais ocupam grande parte do tempo da aula, dispendendo esforços de alunos e professores, não parecem ser tão problemáticos assim para o sucesso da comunicação, tais como, por exemplo: o "s" da terceira pessoa, preposições redundantes, falha no uso das tag questions, omissão ou uso demasiado de artigos definidos e indefinidos e a própria pronúncia do "the" que nem mesmo os nativos falam da mesma forma. (SEIDLHOFER, 2004, p.219). Assim, melhor seria trabalhar a competência de se conseguir negociar e interagir com falantes de diferentes línguas maternas, ao invés de se almejar falar corretamente uma língua monolítica que muitas vezes nem existe.

O ensino de línguas ainda é visto por alguns como não social e desligado de aspectos identitários. O que se faz necessário nesse momento, portanto, não é enfatizar as competências técnicas e linguísticas, mas trazer para o ambiente de estudo questões que colaborem para que traços de língua/identidade dos sujeitos 
envolvidos no processo não sejam apagados (PENNYCOOK, 2001). Com efeito, é relevante “[...] possibilitar que os alunos possam aprender e consequentemente se comunicar (geralmente depois de deixar a escola) com qualquer variedade nativa ou não nativa [...]” (SEIDLHOFER, 2004, p.227).

Todas essas colocações nos fazem refletir sobre a formação de professores. Nesse contexto essa formação precisa ser compreendida de forma mais ampla, os professores de inglês precisam entender as implicações da expansão sem precedentes da língua inglesa e as complexas decisões que irão ter que tomar, pois a concepção de que temos um inglês padrão e de que a sala de aula é neutra e alheia a pensamentos críticos e identitários não é mais tão confiável, e saber lidar com a pluralidade em sala de aula de forma a respeitar as identidades é uma necessidade (SEIDLHOFER, 2004).

Os professores, mais do que serem apenas treinados para trabalhar com técnicas pré-formuladas para contextos específicos de ensino, necessitarão de uma formação mais abrangente, a qual os habilite a julgar as implicações do fenômeno do inglês como língua franca em seus contextos de ensino, e a adaptar sua forma de ensinar às necessidades particulares de seus aprendizes.

\section{REFERÊNCIAS}

ASSIS-PETERSON, A.A. Como ser feliz no meio de anglicismos: processos transglóssicos e transculturais. Trabalhos em linguistica aplicada, Campinas, v. 47, n. 2, dec. 2008 . Disponível em:

$<$ http://www.scielo.br/scielo.php?script=sci_arttext\&pid=So 103-

18132008000200004\&lng=en\&nrm=iso $>$. Accesso em: 21 Ago. 2010. doi: 10.1590/So10318132008000200004

BARCELOS, A M. F. Crenças sobre aprendizagem e ensino de línguas: o que todo professor de línguas deveria saber. In: CAMPOS. M. C. P.; GOMES, M. C. A. (Orgs.). Interações dialógicas: linguagem e literatura na Sociedade contemporânea. Viçosa: UFV, 2004.

BLOCK, D. Globalization, transnational communication and the internet. International journal on multicultural societies, v. 6, n. 1, p. 13-28, 2004.

CANAGARAJAH, S. Resisting linguistic imperialism in English treaching. Oxford: Oxford University Press, 1999. Journal, 2007

Lingua franca English, multilingual communities, and language acquisition. The Modern Language Negotiating the local in English as a língua franca. Annual review of Applied Linguistics, v. 26, 2006.

DEZIN, K. N.; LINCOLN, S. Y. (Eds.). Collecting and interpreting qualitative materials. London: Sage publications, 1996.

FERREIRA, A. de J. Aspectos culturais e o ensino de língua inglesa. Línguas \& Letras, Cascavel: Edunioeste, v.1, n.1, p.117-127, 2000.

FERNANDEZ, C.M; FOGAÇA, F. C. Inglês como língua internacional na universidade: rejeição e objeto de desejo. Linguagem ङ ensino, Pelotas, v. 12, n.1, p. 195-225, jan./jun. 2009.

GiL, A. C. Métodos e técnicas em pesquisa social. São Paulo: Atlas, 1999.

GUNTHER, I. I. Como elaborar um questionário Brasília, DF: UNB, Laboratório de pesquisa Ambiental, 2003. (Série Planejamento de Pesquisa nas Ciências Sociais, n. 1)

HALL, S. A identidade cultural da pós-modernidade. Rio de Janeiro: DP\&A editora, 1999.

HOUSE, J. English as a língua franca: a threat to multilinguism? New York: Balckwell, 2003.

JENKINS, J. Current perspectives on teaching world Englishes as English as a lingua franca. Tesol quarterly, v. 40, n. 1, March 2006.

KALVA, J. M.; FERREIRA, A. J. Ensino de inglês como língua franca e a identidade nacional: refletindo sobre a formação de professores. Revista travessias, v. 5, n. 1, p.709-727, 2011.

KRAMSCH, C.; P. SULLIVAN. Appropriate pedagogy. ELT Journal, v. 50, n. 3, p. 199-212, 1996. 
KUMARAVADIVELU, B. O conceito da globalização. In: MOITA LOPES, L. P. da. Por uma linguística indisciplinar. São Paulo: Parábola Editorial, 2006. p. 130-146.

MARCONI, M. de A.; LAKATOS, E. M. Técnicas de pesquisa: planejamento e execução de pesquisa, amostragens e técnicas de pesquisa, elaboração, análise e interpretação de dados. São Paulo: Atlas, 1986.

MOITA LOPES, L. P. Inglês e globalização em uma epistemologia de fronteira: ideologia linguística para tempos híbridos. DELTA, São Paulo, v. 24, n. 2, 2008. Disponível em:

$<$ http://www.scielo.br/scielo.php? script=sci_arttext\&pid=S0102-4502008000200006\&lng=pt\&nrm=iso $>$. Acesso: em 02 jul. 2010. doi: 10.1590/S0 102-44502008000200006.

Oficina de linguísticaaplicada.: a natureza social e educacional dos processos de ensino aprendizagem de línguas. Campinas, SP: Mercado de Letras, 1996.

PAKIR, A. Standards and codification for world Englishes. In: SMITH, L. E.; FORMAN, M. E. (Eds.). World Englishes 2000. Honolulu: University of Hawaiii Press, 1997. p. 169-81.

PENNYCOOK, A. The cultural politics of English as an international language. London: Longman, 1994.

Critical applied linguistics: a critical introduction. Sidney: University of Tecnology, 2001.

PETERSON, A. A. A.; COX, M. I. P. Inglês em tempos de globalização para além do bem e do mal.

Calidoscópio, v. 5, n.1, p. 5-14, jan./abr. 2007.

PHILLIPSON, R. Linguistic imperialism. Oxford: Oxford University Press, 1992.

RAJAGOPALAN, K. Línguas Nacionais como bandeiras patrióticas, ou a linguística que nos deixou na mão. In: SILVA, F. L. da.; RAJAGOPALAN, K. (Orgs.). A Linguística que nos faz falhar: investigação crítica. São Paulo: Parábola Editorial, 2004. p. 11-37.

2003.

Por uma linguistica crítica: linguagem, identidade e a questão ética. São Paulo: Parábola Editorial;

ROBSON, C. Real world research: a resourse for social scientists and practicioners-researchers. Oxford, UK: Black Well Publishers, 2002.

SEIDLHOFER, B. Research perspective on teaching English as a lingua franca. Annual review of Applied Linguistics, v. 24, p. 209-239, 2004.

SALLES, M. R; GIMENEZ, T. Globalização e políticas educacionais: uma reflexão sobre o ensino e a formação de professores de língua inglesa no contexto brasileiro. Entretextos (UEL), v. 8, p. 150-160, 2008.

WOODWARD, K. Identidade e diferença: uma introdução teórica e conceitual. In: In: SILVA, T. T. da (Org). Identidade e diferença: a perspectiva dos estudos culturais. Rio de Janeiro: Vozes, 2005. p. 7-69.

Recebido em 29/o6/11. Aprovado em 13/02/12. 